\title{
Book Review—Diagnostic pathology: placenta, second edition
}

\section{Jane Esther Dahlstrom ${ }^{1}$}

Received: 6 April 2019 /Revised: 14 April 2019 / Accepted: 18 April 2019/Published online: 10 May 2019

(C) Springer-Verlag GmbH Germany, part of Springer Nature 2019

The second edition of this placental pathology text, as the authors describe in their forward, aims to complement existing classic placental pathology literature with printed and web-based versions. The authors achieve this. They are to be commended on their comprehensive atlas style approach to the diagnoses using high quality illustrative macroscopic and microscopic photomicrographs. The updated terminology and diagnostic criteria to reflect the international consensus statements, published in 2016, [1] are also valued. Comments like the "key elements to report," "pathological interpretation pearls," "sections to be submitted," and "include in the final diagnosis" enhance the value of the text. The reference tables, summary tables, and templates for reporting of placentas are useful. The selected references chosen are appropriate although this reviewer does prefer aligning statements with published evidence. The web-based version is easy to navigate, allows you to highlight text of interest, add personal notes, and hyperlink to the PubMed site for a reference.

What might improve future editions? I would consider reducing the repetition in the book in relation to both the descriptions and illustrations. While important, entities like meconium-associated vascular necrosis are discussed, in varying depth, three times across the book. Some of the images are also essentially duplicated. Perhaps, consideration to cross-referencing in later chapters would reduce this repetition, allowing this book to be more of an ideal compendium. The editors might also like to review the layout of the book, placing all normative charts more consistently in the Appendix. In addition, this reviewer found the approach of image placement related to text in the printed version to be inconsistent, reducing the ease of correlating the words with the excellent illustrations. With the online version, it is easier to access the images but consideration could be given to hyperlinking between the text and images. The bullet format, while aimed at ease of reading, is sometimes not consistent in style. For example, in the section on gross evaluation of the placenta, detail is provided under a few summary bullet points about findings significance but more usually, and I think appropriately, it is discussed later under a subheading in a systematic way. The index, while excellent for locating the text of a disease in the printed version, does not also provide the page number of the photomicrographs for that entity. The aforementioned are just reflections and are not meant to detract from my overall impression that this publication achieves it aims, and is especially suited to pathologists in training or those pathologists looking for high-quality images and key facts, of placental pathology.

Diagnostic Pathology: Placenta, 2nd edition Amy Heerema-McKenney, Edwina J Popek \& Monique E De Paepe eBook ISBN: 9780323609739

Hardcover ISBN: 9780323609715

Published Date: 26th November 2018

$456 \mathrm{pp}$.

$£ 183.99$

\section{Reference}

1. Khong TY et al (2016) Sampling and definitions of placental lesions: Amsterdam placental workshop group consensus statement. Arch Pathol Lab Med 140(7):698-713

Publisher's note Springer Nature remains neutral with regard to jurisdictional claims in published maps and institutional affiliations.

Jane Esther Dahlstrom

jane.dahlstrom@act.gov.au; https://health.act.gov.au

1 Australian National University Medical School, Canberra Hospital, Building 10 Level 1, PO Box 11, Woden, ACT 2606, Australia 